\title{
THE EFFECT OF GLUCAGON ON THE BLOOD GLUCOSE LEVEL AND THE CLINICAL STATE IN THE PRESENCE OF MARKED INSULIN HYPOGLYCEMIA ${ }^{1,2}$
}

\author{
BY JEROME L. SCHULMAN AND STANLEY E. GREBEN
}

(From the Department of Psychiatry of The Johns Hopkins Hospital, Baltimore, Md.)

(Submitted for publication April 30, 1956; accepted October 4, 1956)

The increasing evidence that glucagon is a naturally occurring hormone has led to considerable interest and speculation as to its possible metabolic roles. The possibility of obtaining glucagon in increasingly pure preparations and the final obtainment of a crystalline preparation (1) have added impetus to this interest.

The presence of a hyperglycemic contaminant was one of the suggestions advanced to explain the initial rise in the blood sugar level which followed the administration of some preparations of insulin. There is general agreement that glucagon can cause at least a temporary rise in the blood sugar level in the presence of insulin. However, considerable interest still centers around the question of the relative effects of insulin and glucagon on the blood sugar level (2-5).

It was believed that there would be some advantage in exploring the effect of glucagon in patients who had received massive doses of insulin. This situation obtains in the insulin coma treatment of psychiatric patients. It was also considered that glucagon could serve as a useful means of terminating insulin coma. The present report deals with these questions.

\section{MATERIALS AND METHODS}

The patients used for this study were all hospitalized at The Henry Phipps Psychiatric Clinic and were diagnosed as exhibiting schizophrenic reactions. There were 11 patients, of whom 6 were women and 5 were men. They ranged in age from 16 to 48 years with an average age of 28 years. They were all in good physical health.

All of these patients were receiving insulin coma therapy as part of the therapeutic regimen for their

\footnotetext{
1 This investigation, under the direction of Dr. John C. Whitehorn, was supported by a research grant (M-1085) from the National Institute of Mental Health of the National Institutes of Health, Public Health Service.

2 The glucagon employed in this study was kindly supplied by Dr. W. R. Kirtley of Eli Lilly and Company. Portions of lots numbered 208-158B-214, 208-158B-214A, and 258-234B-30A were included.
}

psychiatric illness. A commercial preparation of regular insulin was employed. The dose of insulin varied from 60 to 2000 units with an average dose of 593 units for each treatment. On each treatment day the patient, in a fasting state, received crystalline insulin intramuscularly at 7:00 A.M. Typically, the patient entered coma at about 9:00 A.M. and the coma was terminated at about 10:30 A.M. At the time of termination the patient was almost invariably in third or fourth stage coma according to the criteria of Himwich (6). The usual course of treatments consisted of about 60 comas although there was some variation and glucagon was not employed for the termination of each coma.

Insulin comas were terminated with glucagon in 141 instances. Of this total glucagon was administered intravenously 97 times, intramuscularly 22 times and subcutaneously on 22 occasions. Following 61 of these terminations of coma the response to glucagon was followed with blood sugar determinations. Blood was withdrawn from an antecubital vein several minutes before the administration of the glucagon and at 5, 10, 15, $20,30,40$, and 50 minutes following the administration of the glucagon. A separate venipuncture was performed for each determination. There was some variation in the timing of the withdrawals for technical reasons. On two occasions more than one dose of glucagon was administered. The coma was considered clinically terminated when the patient was able to respond verbally to questions or was able to take fluids by mouth with minimal difficulty.

In addition, seven of the patients had a series of three tests in which glucagon was administered on days when they had not received insulin. In each instance the first of the three tests was performed the day before insulin coma therapy was instituted, the second on the day after they had reached the highest insulin dose in the series of comas and the third on the day following the last insulin coma treatment. A fasting specimen of blood was withdrawn and the glucagon was administered as a rapid intravenous dose. For the tolerance tests the dose was always $0.01 \mathrm{mg}$. per $\mathrm{kg}$. of body weight. ${ }^{3}$ Blood samples were then withdrawn at $10,20,30,45,60$, and 120 minutes.

Early in the work the determination of the blood sugar

3 Throughout the paper the glucagon dosage is reported in terms of total milligrams of solids in the glucagon solution. In the lots of glucagon employed in the study about 50 per cent of the solids was actually glucagon. 
was performed by the method of Folin (7). The later determinations were performed by the Nelson modification of the Somogyi method (8). In each case the determination was performed on $1 \mathrm{cc}$. of whole blood. All of the Somogyi determinations were done in duplicate. Most of the values reported for blood sugar are reported as milligrams change in blood sugar which tends to minimize the differences due to method.

\section{RESULTS}

\section{Clinical findings}

On the 97 occasions when the glucagon was administered intravenously the dose of glucagon varied from 0.003 to $0.3 \mathrm{mg}$. per $\mathrm{kg}$. of body weight. However, most of the time the dose was between 0.01 and $0.1 \mathrm{mg}$. per $\mathrm{kg}$. of body weight. On 95 of the 97 occasions the coma was clinically terminated. On two occasions the patient did not awaken. Both of these occurred in the same patient. The dose of glucagon in these two instances was 0.01 and $0.04 \mathrm{mg}$. per $\mathrm{kg}$. of body weight. On one of these occasions the patient also failed to awaken with intravenous glucose and had a prolonged coma. Successful terminations were accomplished on this patient on other occasions.

On the 22 occasions when glucagon was administered intramuscularly the dose of glucagon varied from 0.02 to $0.1 \mathrm{mg}$. per $\mathrm{kg}$. of body weight. Nineteen of these terminations were clinically successful. On 3 occasions the patients failed to awaken and responded to intravenously administered glucose.

Glucagon alone was administered subcutaneously on 11 occasions with 7 awakenings and 4 failures. Glucagon was also administered subcutaneously with the addition of 75 turbidity reducing units of a hyaluronidase preparation 11 times. There were 8 successful awakenings and 3 failures.

The average awakening time for all of the intravenous terminations was 13.5 minutes with a range of 4 to 22 minutes. The average awakening time for all of the intramuscular terminations was 16.9 minutes with a range of 7 to 24 minutes. In computing these averages an awakening time of 30 minutes was considered a failure. It was felt that there were insufficient successful subcutaneous terminations to allow for a meaningful average.

At no time was any adverse effect noted either locally or generally following the administration of glucagon.

\section{Characteristics of blood sugar response}

The blood sugar levels just prior to the administration of glucagon averaged $15.0 \mathrm{mg}$. per cent by the Folin method ( 7$)$ and 5.0 by the Nelson modification of the Somogyi method (8).

Invariably there was a rise in the blood sugar by the time the first blood specimen was obtained following the administration of the glucagon. This usually occurred at 5 minutes and demonstrates the rapidity of the onset of the action of glucagon.

When the glucagon was administered intravenously the average time of the maximal response of the blood sugar was 25.2 minutes, with a range of 17 to 40 minutes. When given intramuscularly the average time of the maximal response was 31.6 minutes with a range of 15 to 56 minutes.

The maximal rise in blood sugar averaged 33.6 $\mathrm{mg}$. per cent with a range of 8 to $59 \mathrm{mg}$. per cent when the glucagon was given intravenously. When given intramuscularly the average rise was $22.2 \mathrm{mg}$. per cent with a range of 6 to $48 \mathrm{mg}$. per cent. The actual rises were probably a little higher, in view of the probability that the highest point was missed because of relatively infrequent blood specimens.

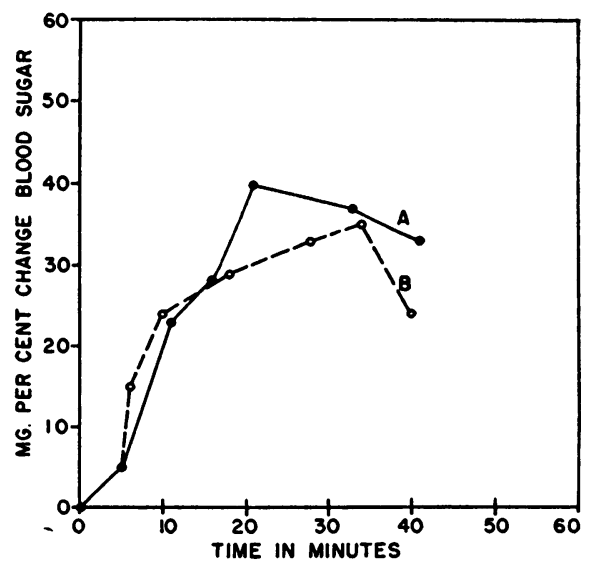

Fig. 1. The Effect of Identical Doses of Glucagon upon the Blood Sugar in the Presence of Comas of Equivalent Depth Produced by Different Doses of INSULIN

Both curves were obtained in the same patient with a glucagon dose of $0.05 \mathrm{mg}$. per $\mathrm{kg}$. of body weight. AFollowing the administration of 2,000 units of insulin. $\mathrm{B}-$ Following the administration of 850 units of insulin. 


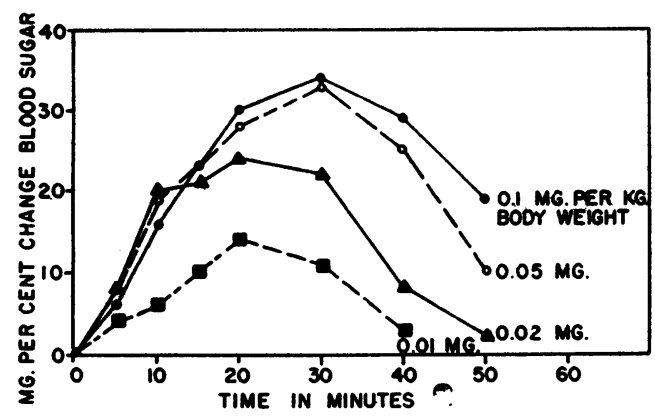

Fig. 2. The Average Responses to a Variety of Glucagon Doses in Five Patients

A total of 35 tests is included, with equivalent doses averaged. In each case the number represents the dose of glucagon in $\mathrm{mg}$. per $\mathrm{kg}$. of body weight.

\section{Effect of dose of insulin}

As a patient progresses through a series of insulin comas there is a wide variation in the dose of insulin required to produce a coma of equivalent depth. In terminating insulin comas with glucagon it became clinically evident that the effectiveness of a given dose of glucagon did not depend on the dose of insulin but rather on the degree to which that dose had been effective in producing coma.

Figure 1 records the blood sugar responses in the same patient on two occasions. Each time the dose of glucagon was $0.05 \mathrm{mg}$. per $\mathrm{kg}$. of body weight administered intravenously. The patient was in third stage coma in both instances. Curve A was obtained early in the course of therapy when 2000 units of insulin was administered. Curve B was obtained later when 850 units of insulin was administered. The blood sugar rise with identical doses of glucagon is comparable in the two cases despite the great difference in the dose of insulin.

\section{Effect of dose of glucagon}

Five patients were selected as having had a sufficient variation in the glucagon dose for comparison. In these patients there was a total of 35 curves obtained where the glucagon had been administered intravenously. Whereas very small doses of glucagon would terminate comas successfully, larger doses evoked a greater and more sustained blood sugar response. This was true for each of the 5 patients. Figure 2 is summary of all 35 curves in 5 patients with similar doses av- eraged. One notes the clear relationship between the dose of glucagon and the amplitude and duration of the response.

\section{Effect of route of administration}

There was a consistently greater rise in the blood sugar following the administration of an intravenous dose of glucagon during the course of coma than the rise obtained following an intramuscular dose. The difference in comparable situations was usually evident in the results five minutes after the administration of the drug. The duration of action did not appear to be different as a result of a different route of administration.

\section{Multiple doses of glucagon}

Figure 3 records the blood sugar response to $0.05 \mathrm{mg}$. of glucagon per $\mathrm{kg}$. of body weight administered intravenously at 0,20 , and 42 minutes. In each case the repeated dose evoked a response, as evidenced by the prolongation of the rise in the blood sugar beyond the point that was obtained in any patient when one dose of glucagon was given. Another patient received two doses of glucagon at 30-minute intervals with a similar result.

\section{Effect of a course of insulin coma on response to glucagon}

In each of the 7 patients on whom the 3 glucagon tests were performed (prior to insulin, on the day following the highest dose of insulin, and

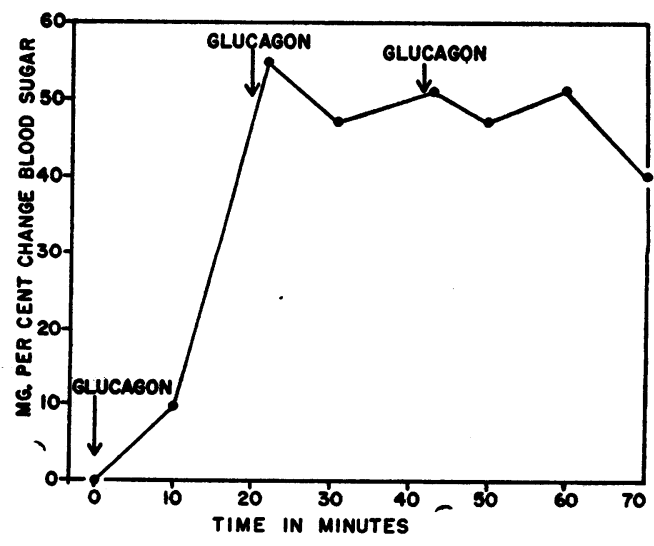

Fig. 3. The Response to Multiple Doses of GLUCAgon

The dose of glucagon was $0.05 \mathrm{mg}$. per kg. of body weight administered at 0,20 , and 42 minutes. 


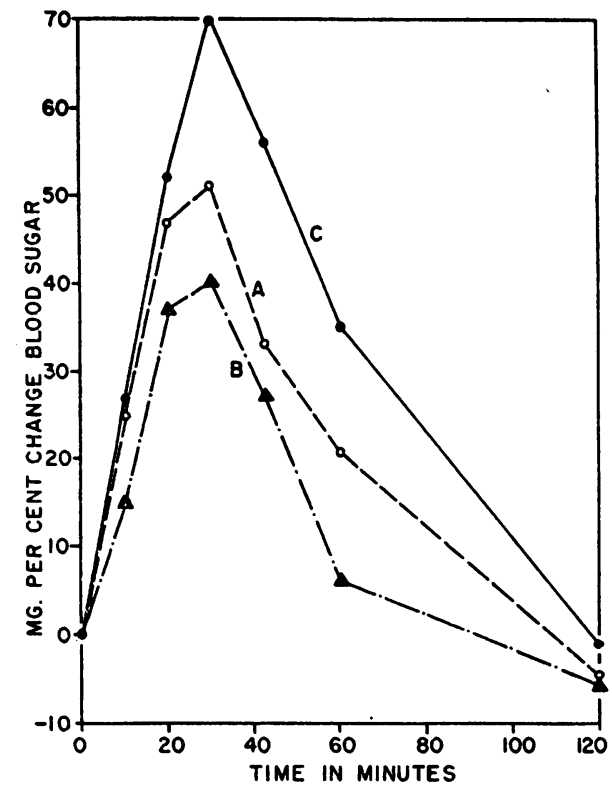

Fig. 4. The Average Change in the Response to Glucagon during the Course of Insulin Coma Therapy in Seven Patients

The dose of insulin for each curve was $0.01 \mathrm{mg}$. per $\mathrm{kg}$. of body weight. No insulin was administered on the day of the test. A-The day prior to the institution of insulin therapy. B-The day following the maximal dose of insulin. C-The day following the last insulin treatment.

on the day following the last insulin treatment), it was noted that the maximal rise was greatest in the curve obtained at the termination of the course of insulin treatments. These results are illustrated in Figure 4 which represents the average of these curves for the seven patients. For the differences in the level attained before insulin and following the completion of therapy $\mathrm{P}=<0.02$ at the 30 and 45 -minute intervals. The findings are taken to be suggestive of increased response to glucagon developing during the course of insulin coma therapy.

\section{$A$ comparison between the blood sugar response to glucagon in a fasting state and in insulin coma}

There were 5 patients who had glucagon administered prior to the onset of insulin coma therapy with suitable blood sampling and who had a large enough number of comas terminated with glucagon with sufficient variation in glucagon dosage to form an adequate basis for comparison. A total of 35 intravenous terminations of coma ac- companied by blood sampling was performed on this group. All of the tests before insulin therapy were performed with $0.01 \mathrm{mg}$. of glucagon per $\mathrm{kg}$. of body weight.

None of the patients achieved a comparable rise in blood sugar following the administration of glucagon in insulin coma when the dose of glucagon was the same as was employed for the tests before insulin. One patient achieved a greater rise in blood sugar following termination on 7 occasions when the dose of glucagon was between 0.05 and $0.1 \mathrm{mg}$. per $\mathrm{kg}$. of body weight. However, this patient had the unusually low maximal rise of 26 mg. per cent on his test prior to insulin coma therapy. The other 4 patients failed to produce as great a rise in the blood sugar in the termination of insulin coma on 26 occasions as they did on the previous test. The glucagon dosage varied from 0.003 to $0.1 \mathrm{mg}$. per $\mathrm{kg}$. of body weight, each patient having received the dose of $0.1 \mathrm{mg}$. per $\mathrm{kg}$. of body weight on at least 1 occasion.

One of these 4 patients received a dose of 0.2 mg. per kg. of body weight on 1 occasion. The rise in blood sugar following the termination of insulin coma with this dose was greater than that obtained on the test performed prior to insulin

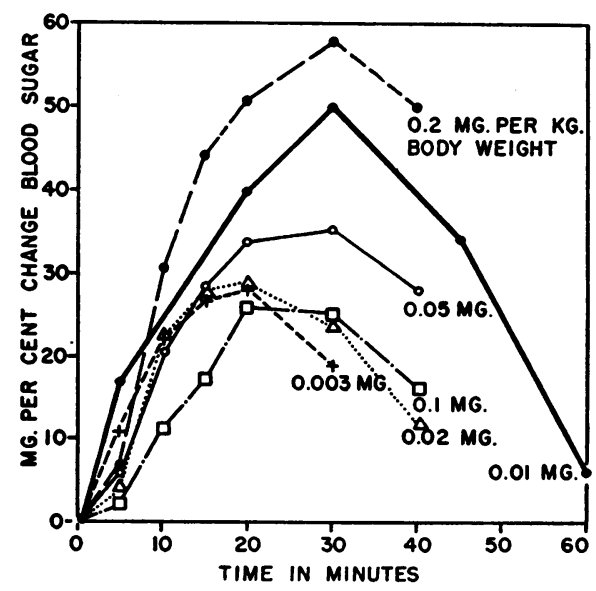

Fig. 5. A Comparison of the Response to Varying Doses of Glucagon While in Insulin Coma with That Obtained Prior to the Institution of Insulin THERAPY

All curves represent the responses of one patient. The heavy line is the result of the tolerance test performed prior to the institution of insulin therapy. The other curves were obtained from studies performed while the patient was in insulin coma. The numbers represent the dose of glucagon in mg. per kg. of body weight. 
therapy. Figure 5 demonstrates the rise achieved with each dose of glucagon in the termination of insulin coma in this patient as well as the results of the test performed prior to insulin coma therapy.

\section{DISCUSSION}

The fact that glucagon is capable of causing a rise in the blood sugar following the administration of moderate doses of insulin is well documented. The demonstration that glucagon is capable of raising the blood sugar following the massive insulin doses employed in this study is a tribute to its extraordinary physiological potency. In a sense this is not surprising for there is no known direct antagonism between insulin and glucagon. The localization of the main if not the sole action of glucagon at the site of liver phosphorylase (9) where insulin has no direct effect would seem to indicate that glucagon would continue to pour glucose into the blood stream independent of the action of insulin.

However, once the glucose is liberated into the blood stream the glucagon no longer has any influence over it and the actions of insulin would tend to remove it. Since the glucose is being removed from the blood stream at a rapid rate, the level of blood glucose is not a good index of the amount of glucose being liberated from the liver through the action of glucagon. The level of glucose in the blood is a reflection of the relative efficacy of those substances which tend to raise the blood sugar and those which tend to lower it. The interrelation of other substances, particularly those elaborated by the pituitary and adrenal glands, is not clear. However, one would expect that the effects of these hormones are manifesting themselves prior to the introduction of glucagon.

From the foregoing, one would conclude that the amount of glucose liberated into the bloodstream following a dose of glucagon would be at least as high during insulin hypoglycemia as when administered without insulin, even though this would not be reflected in the blood sugar levels. Theoretically this concept would appear to be sound. Some of our data would make one question this simple explanation of the relative actions of glucagon and insulin. There is agreement that a relatively small dose of glucagon will cause a maximal rise in blood sugar and further increases in dosage will have no additional effect $(3,4,10)$. In preliminary studies on patients not receiving insulin we have found that this dose is definitely less than $0.01 \mathrm{mg}$. per $\mathrm{kg}$. of body weight. In the presence of insulin hypoglycemia an increased dose of glucagon caused an increased response in the blood sugar over the entire range studied. This was true up to a dose of glucagon of $0.2 \mathrm{mg}$. per $\mathrm{kg}$. of body weight, 20 times the dose mentioned above. It is difficult to understand why insulin should alter this relationship. It is likely that increased liver glycogen and low blood sugar would tend to increase the amount of glucose liberated, but it is difficult to see how these factors could change the amount of glucagon necessary to produce maximal activation of the phosphorylase mechanism. One would tend to believe that there are additional facts which have a rather important bearing on this situation, but which are not as yet available.

Further evidence that the dose of glucagon necessary to produce a maximal response increases as a result of the effect of insulin is provided by the result of the administration of multiple doses of glucagon. Staub and Behrens (4) have shown in cats that a second dose of glucagon, administered after 25 minutes, had an effect if the first dose had not produced maximal stimulation. If the first dose was sufficient to produce maximal stimulation there was no response to the second dose. We have noted an appreciable response to the second dose even though the first dose was $0.05 \mathrm{mg}$. per kg. of body weight. Without insulin this dose would have been more than sufficient to produce a maximal response.

The response of the blood sugar to a given dose of glucagon was definitely less during the course of insulin hypoglycemia than prior to the administration of insulin. This is most likely due not to a decrease of the amount of glucose liberated from the liver but rather to its rapid removal from the blood stream. In spite of this our data leave open the theoretical possibility that if sufficient glucagon were given the response would have been even greater during insulin hypoglycemia. This actually occurred in the 1 patient who had a dose of 0.2 mg. of glucagon per kg. of body weight.

It is clear that the response to an intravenous dose of glucagon is greater than that to an intramuscular dose. This is manifested mainly by the 
difference in the maximal rise but also by the rapidity of the rise. On clinical grounds the subcutaneous route seems to be considerably poorer than either of the other routes.

It is difficult to evaluate fully the difference in response between patients because of the number of variables involved and particularly because of the problems involved in adopting standards for estimation of the coma. However, the range of variation does not appear to be striking in comparison with the range of response with other carbohydrate tolerance tests and with the range of response to glucagon in patients not receiving insulin.

The change in sensitivity to glucagon during the course of insulin comas also is difficult to evaluate. The weight of these patients tended to increase as a result of the insulin therapy, and the dose of glucagon was administered on the basis of body weight. However, it is not believed that the increase in the dose of glucagon explains the difference, as all of the doses probably produced a maximal response. Neither is the difference due to the fact that the last test was performed on the day after the patient received insulin therapy, since there was a difference between the results of tests performed at the time of the highest insulin dose and those performed at the end of therapy. The highest dose of insulin is almost invariably given very early in therapy. Root (11) has reported an increase in sensitivity to glucagon in rats upon chronic administration. During the course of insulin coma one would expect that the body is producing more glucagon than normally. Perhaps one might view this as a chronic administration of large doses of glucagon and conclude that the increased sensitivity is analogous to the increased sensitivity obtained by Root. The exogenous glucagon administered in the termination of insulin comas may also have played a role, although this phenomenon also occurred in patients who had very few glucagon terminations. The increased sensitivity may well be due to increased liver glycogen stores produced by the insulin.

One is struck with the apparent innocuousness of the glucagon. At no time did any noxious reaction occur which could be attributed to the glucagon.

It would appear that glucagon is a satisfactory drug for the routine termination of insulin comas when given intravenously. Further study is indicated to see whether the intramuscular route will be satisfactory. The addition of a hyaluronidase preparation may well make this feasible. There are several advantages to the use of glucagon for this purpose. One is the decreased volume of injection and decreased viscosity as compared with glucose for intravenous administration. Another advantage is the absence of local reactions, such as thrombosis, at the site of injection. When compared with termination by tube feeding it is less time consuming, technically easier, faster, appears to have a decreased incidence of gastro-intestinal disturbances and decreases the danger of aspiration of gastric contents. One other possible advantage which has yet to be demonstrated is that of decreased weight gain during the course of insulin coma therapy, for excessive weight increase occurs in some patients. Since we are employing the patient's own glucose to terminate the coma this may prove to be true. A much larger series will have to be accumulated to substantiate this possibility.

One disadvantage in the use of glucagon in the routine termination of insulin coma is the necessity that the patient take food by mouth shortly after awakening to prevent his lapsing back into coma. This is also true, however, when intravenous glucose is used for termination. The awakening is not as rapid after glucagon as it is after intravenous glucose where the patient awakens within a few minutes, a fact which may possibly be advantageous (12).

\section{SUMMARY}

1. Glucagon has been administered on 141 occasions to patients in insulin coma.

2. Within the dosage limits explored the greater the dose of glucagon the greater was the resultant rise in blood sugar. This was true with doses of glucagon that markedly exceeded the dose that would ordinarily be expected to produce a maximal response.

3. The intravenous route was found to be superior to the intramuscular route of administration. The subcutaneous route was much poorer than either of the other routes.

4. Responsiveness to glucagon increased during the course of insulin coma therapy. 
5. Glucagon was usually successful in terminating insulin coma and it is suggested that glucagon has some advantages as a means of routine termination of insulin coma and that a further clinical trial is warranted.

\section{ACKNOWLEDGMENTS}

We are most indebted to Dr. John C. Whitehorn for his guidance, advice and suggestions. Miss Betty Blevins has been invaluable in providing technical assistance. Mrs. Pauline Weade, R.N. and the other members of the nursing staff have been most gracious in providing their help, without which we could not have performed this study. We would also like to thank Mrs. Frances Grainger for assisting in the preparation of the manuscript.

\section{REFERENCES}

1. Staub, A., Sinn, L., and Behrens, O. K., Purification and crystallization of glucagon. J. Biol. Chem., 1955, 214, 619.

2. Root, M. A., Ellis, J., and Staub, A., Effect of glucagon on insulin hypoglycemia. Proc. Soc. Exper. Biol. \& Med., 1954, 85, 507.

3. Carson, M. J., and Koch, R., Clinical studies with glucagon in children. J. Pediat., 1955, 47, 161.
4. Staub, A., and Behrens, O. K., The glucagon content of crystalline insulin preparations. J. Clin. Invest., 1954, 33, 1629.

5. Kirtley, W. R., Waife, S. O., Helmer, O. M., and Peck, F. B., Effect of purified glucagon (hyperglycemic-glycogenolytic factor, HGF) on carbohydrate and corticoid metabolism in normal and diabetic subjects. Diabetes, 1953, 2, 345.

6. Himwich, H. E., The physiology of the "shock" therapies. Psychiatric Quart., 1944, 18, 357.

7. Folin, O., Two revised copper methods for blood sugar determination. J. Biol. Chem., 1929, 82, 83.

8. Nelson, N., A photometric adaptation of the Somogyi method for the determination of glucose. J. Biol. Chem., 1944, 153, 375.

9. Sutherland, E. W., The effect of the hyperglycemic factor of the pancreas and of epinephrine on glycogenolysis. Recent Prog. Hormone Research, 1950, 5, 441.

10. Loube, S. D., Campbell, E. D., and Mirsky, I. A., Administration of the hyperglycemic-glycogenolytic factor of the pancreas to non-anesthetized and anesthetized subjects. Proc. Soc. Exper. Biol. \& Med., 1950, 75, 161.

11. Root, M. A., Effect of glucagon on glycogen in rats and rabbits. Endocrinology, 1956, 59, 340.

12. Sakel, M., The classical Sakel shock treatment. A reappraisal. J. Clin. Exper. Psych., 1954, 15, 255. 